\title{
Effect of telmisartan on selected adipokines, insulin sensitivity, and substrate utilization during insulin-stimulated conditions in patients with metabolic syndrome and impaired fasting glucose
}

Petr Wohl, Eva Krušinová, Martin Hill ${ }^{1}$, Simona Kratochvílová, Kateřina Zídková, Jan Kopecký, Tomáš Neškudla,

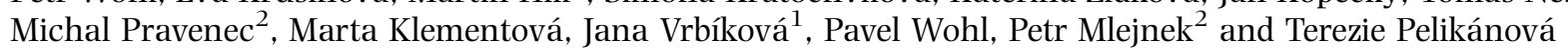

Diabetes Center, Institute for Clinical and Experimental Medicine, Vídeňská 1958/4, Prague 140 21, Czech Republic, ${ }^{1}$ Institute of Endocrinology,

Narodni 8, Prague 116 94, Czech Republic and ${ }^{2}$ Institute of Physiology, Academy of Sciences of the Czech Republic, Videnska 1083, Prague 142 20, Czech Republic

(Correspondence should be addressed to T Pelikánová; Email: terezie.pelikanova@ikem.cz)

\begin{abstract}
Objective: Telmisartan improves glucose and lipid metabolism in rodents. This study evaluated the effect of telmisartan on insulin sensitivity, substrate utilization, selected plasma adipokines and their expressions in subcutaneous adipose tissue (SAT) in metabolic syndrome.

Design and methods: Twelve patients with impaired fasting glucose completed the double-blind, randomized, crossover trial. Patients received telmisartan $(160 \mathrm{mg} / \mathrm{day})$ or placebo for 3 weeks and vice versa with a 2 -week washout period. At the end of each period, a hyperinsulinemic euglycemic clamp (HEC) combined with indirect calorimetry was performed. During HEC (0, 30, and $120 \mathrm{~min})$, plasma levels of adipokines were measured and a needle biopsy ( 0 and $30 \mathrm{~min})$ of SAT was performed. Results: Fasting plasma glucose was lower after telmisartan compared with placebo $(P<0.05)$. There were no differences in insulin sensitivity and substrate utilization. We found no differences in basal plasma adiponectin, resistin and tumour necrosis factor $\alpha$ (TNF $\alpha$ ), but an increase was found in basal leptin, after telmisartan treatment. Insulin-stimulated plasma adiponectin $(P<0.05)$, leptin and resistin $(P<0.001)$ were increased, whereas TNF $\alpha$ was decreased $(P<0.05)$ after telmisartan treatment. Expression of resistin, but not adiponectin, TNF $\alpha$ and leptin was increased after telmisartan treatment.

Conclusions: Despite the decrease in fasting plasma glucose, telmisartan does not improve insulin sensitivity and substrate utilization. Telmisartan increases plasma leptin as well as insulin-stimulated plasma adiponectin, leptin and resistin, and decreases plasma TNF $\alpha$ during HEC. Changes in plasma adipokines cannot be explained by their expressions in SAT. The changes in plasma adipokines might be involved in the metabolic effects of telmisartan in metabolic syndrome.
\end{abstract}

European Journal of Endocrinology 163 573-583

\section{Introduction}

Several large intervention trials have demonstrated that angiotensin II type 1 receptor antagonists (ARBs) reduce the incidence of new-onset diabetes by $20-25 \%$ $(1,2)$. The protective effects of ARBs during the development of diabetes are probably independent of their antihypertensive properties $(3,4)$.

However, the mechanisms underlying the effect of ARBs on glucose metabolism are not fully understood. Experimental evidence has been accumulated that insulin resistance (IR) may be improved by interrupting renin-angiotensin system (5). All ARBs have been shown to improve insulin sensitivity in experimental and in vitro studies through multiple mechanisms, including increase in muscle blood flow, decreased sympathetic nervous activity, enhanced insulin signalling and adipose-tissue remodelling $(5,6)$. Angiotensin II inhibits pre-adipocyte differentiation into mature adipocytes, which impairs the fat cells' ability to store fat (6). This in turn results in accumulation of fats in the liver, the skeletal muscle, and the pancreas, which worsens IR. Impaired fat cells produce excessive amounts of pro-inflammatory cytokines (tumour necrosis factor $\alpha$ (TNF $\alpha$ ), interleukin (IL) 6 , resistin, and others), whereas the insulin-sensitizing cytokines such as adiponectin are reduced (6). Blocking the angiotensin II receptor with ARBs decreases the adipocyte size (7), promotes differentiation of pre-adipocytes to mature adipocytes, and prevents the ectopic fat accumulation (8). In addition, ARBs may alter the adipokine profile.

It has been shown that ARBs increase the adiponectin protein content in isolated adipocytes (9). Increases in plasma adiponectin concentrations after 
ARB treatment have been found also in human subjects by some (10-12), but not all, groups (13). The actual knowledge of the physiological roles of resistin and $\mathrm{TNF} \alpha$ in altering muscle glucose and lipid metabolism is more controversial, but each has been shown to directly impair insulin signalling and consequently insulin-stimulated glucose uptake in muscles (14). The role of resistin is less understood. It is implicated in IR in rats but probably not in human subjects. Moreover, other adipokines (such as adiponectin and leptin) in physiological concentrations are insulin sparing as they stimulate $\beta$ oxidation of fatty acids in skeletal muscle. The effect of ARBs on adipokines in vivo in human subjects has not been systematically evaluated until now.

Human studies investigating the effect of ARBs on insulin sensitivity are not conclusive. Most of the randomized, placebo-controlled or head-to-head studies using the hyperinsulinemic euglycemic clamp (HEC) technique for estimation of insulin sensitivity have found no significant effect of ARBs on insulin action in human subjects $(5,15,16)$. However, there is evidence that certain ARBs have a further effect on insulin sensitivity, which is mediated through peroxisome proliferator-activated receptor $\gamma$ (PPARG). PPARG is a nuclear transcription factor which triggers the expression of multiple genes involved in glucose and lipid metabolism (17). Not all ARBs have been shown to bind to PPARG; the strongest activity has been seen with telmisartan $(4,17$, 18). Based on rodent experiments, it can be hypothesized that the activation of PPARG may be involved in the ability of telmisartan to increase muscle fatty acid oxidation and energy expenditure (EE) (19). The in vivo effects of telmisartan on insulin sensitivity and substrate oxidation estimated by HEC combined with indirect calorimetry have not been studied in human subjects so far.

The aim of our study was to evaluate in vivo effects of telmisartan on insulin sensitivity, substrate utilization, basal and insulin-stimulated plasma concentrations of selected adipokines and their expressions in subcutaneous adipose tissue (SAT) in patients with impaired fasting glucose and metabolic syndrome.

\section{Subjects and methods}

\section{Subjects}

We enrolled 12 male patients with metabolic syndrome defined according to the NCEP-ATPIII criteria, revised in 2005 (20). Impaired fasting glucose was an obligate criterion for enrolment in the study. One patient had both impaired fasting glucose and impaired glucose tolerance (confirmed by an oral glucose tolerance test). Only male subjects participated in the study in order to exclude variability in insulin sensitivity in women according to menstrual cycle and childbearing potential and with respect to sexual dimorphism of adipokines. Characteristics of study group are shown in Table 1.
Table 1 Characteristics of study group.

\begin{tabular}{ll}
\hline$n$ & \\
Age (years) & 12 \\
BMl $\left(\mathrm{kg} / \mathrm{m}^{2}\right)$ & $50.0 \pm 6.02$ \\
Waist $(\mathrm{cm})$ & $29.0 \pm 4.37$ \\
Systolic blood pressure $(\mathrm{mmHg})$ & $104.6 \pm 7.8$ \\
Diastolic blood pressure $(\mathrm{mmHg})$ & $133.0 \pm 12.0$ \\
HbAlc $(\%)$ & $91.3 \pm 10.0$ \\
Total cholesterol (mmol/l) & $3.86 \pm 0.44$ \\
HDL cholesterol (mmol/l) & $5.51 \pm 1.1$ \\
LDL cholesterol $(\mathrm{mmol} / \mathrm{l})$ & $0.99 \pm 0.12$ \\
Serum triglycerides $(\mathrm{mmol} / \mathrm{l})$ & $3.2 \pm 1.22$ \\
Plasma glucose $120 \mathrm{~min}, \mathrm{OGTT}(\mathrm{mmol} / \mathrm{l})$ & $2.71 \pm 1.4$ \\
Fasting plasma glucose $(\mathrm{mmol} / \mathrm{l})$ & $7.6 \pm 1.8$ \\
& $6.1 \pm 0.43$ \\
\hline
\end{tabular}

OGTT, oral glucose tolerance test.

Patients enrolled in the study were treatment-naive with regard to oral antidiabetic medication. Antihypertensive treatment was adjusted during the 4-week run-in period as follows: angiotensin-converting enzyme and ARB treatment had been stopped and replaced by metabolic neutral calcium channel blockers. The dose of concomitant calcium channel blocker (if required) was stable during the whole study duration. None of the patients had their dietary intake of salt or protein restricted. Patients with overt diabetes (diagnosed by an oral glucose tolerance test), acute or chronic inflammatory, or other major organ diseases were excluded from the study.

All subjects gave their informed consent with the study protocol that had been reviewed and approved by the local ethics committee. The study was performed in accordance with the Helsinki Declaration and Title 45, Code of Federal Regulations, Part 46, Protection of Human Subjects. The EudraCT number 2006-000490-29 had been issued for our Sponsor's Protocol Code No. 1, 1.1.2006.

\section{Study protocol}

The study was a randomized, placebo-controlled, double-blind, crossover trial consisting of two treatment periods. After a 4-week run-in period, the subjects were randomly assigned to receive telmisartan $160 \mathrm{mg}$ daily (Micardis 80 mg; Boehringer Ingelheim Pharma GmbH, Ingelheim am Rhein, Germany) or placebo for 3 weeks. After a 2-week washout period, the medication was changed and continued for another 3 weeks. Randomization was performed by standard procedure. The code was not broken until all data were entered into a database, which was locked for editing. Drug compliance was assessed by the effect on blood pressure as well as by the study drug accountability. Patients were instructed to adhere to their ordinary lifestyle and avoid changes in food intake, alcohol consumption and exercise during the whole study duration.

At the end of both 3-week periods of treatment with telmisartan or placebo, all patients underwent a $2 \mathrm{~h}$ HEC combined with indirect calorimetry and adipose tissue biopsies. 
Hyperinsulinemic euglycemic clamp The subjects were examined on an outpatient basis after an 8-10 h overnight fast with only tap water allowed ad libitum. The HEC, lasting $2 \mathrm{~h}$, was conducted as described earlier (21). Briefly, a Teflon cannula (VenflonViggo, Helsingborg, Sweden) was inserted into left antecubital vein for infusion of all test substances. A second cannula was inserted in a retrograde manner into a wrist vein of the same hand for blood sampling, and a hand was placed in a heated $\left(65^{\circ} \mathrm{C}\right)$ box to achieve venous blood arterialization. A stepwise primed-continuous infusion $(1 \mathrm{mU} / \mathrm{kg}$ per min of Actrapid HM; NovoNordisk, Copenhagen, Denmark) was administered to acutely raise and maintain the plasma concentration of insulin at $75 \mu \mathrm{U} / \mathrm{ml}$. Plasma glucose concentrations during the clamp were maintained at $5.0 \mathrm{mmol} / \mathrm{l}$ by continuous infusion of $15 \%$ glucose. To prevent hypokalemia during insulin infusion, potassium chloride was added to $15 \%$ glucose infusion $(30 \mathrm{mmol} \mathrm{KCl} / \mathrm{l}$ of glucose). Arterialized blood plasma glucose concentration was determined every 5-10 min. Before the clamp, fasting plasma glucose levels had been checked, and at concentration lower than $6.0 \mathrm{mmol} / \mathrm{l}$, the clamp procedure was started. No glucose was infused until plasma glucose had declined to the clamp-target level.

Needle biopsy of abdominal SAT Needle biopsy of abdominal SAT was performed before $(0 \mathrm{~min})$ and $30 \mathrm{~min}$ into the clamp. Under local anaesthesia $(1 \%$ trimecain in a field block pattern), an incision (3-4 mm) was made through the skin at the lower abdomen, and a subcutaneous fat specimen $(300 \mathrm{mg})$ was obtained by needle aspiration. The samples were washed in $0.9 \%$ natrium chloride solution, immediately frozen by liquid nitrogen, and stored at $-80{ }^{\circ} \mathrm{C}$ until used for RNA extraction.

Indirect calorimetry Substrate utilization and EE were assessed by indirect calorimetry (22). Gas exchange measurements were performed during a $45 \mathrm{~min}$ basal period before starting the insulin infusion and during the last $45 \mathrm{~min}$ period of the clamp. A transparent plastic ventilated hood was placed over the subject's head and made airtight around the neck. A slight negative pressure was maintained in the hood to avoid loss of expired air. A constant fraction of air flowing out of the hood was automatically collected for analysis. Airflow and $\mathrm{O}_{2}$ and $\mathrm{CO}_{2}$ concentrations in expired and inspired air were measured by a continuous opencircuit system (metabolic monitor VMAX; Sensor Medics, Anaheim, CA, USA). Blood samples were taken at 0 and $120 \mathrm{~min}$ of the clamp study to assess plasma levels of selected adipokines and blood urea nitrogen. Urine was collected i) during the night before the study (basal) and ii) during the clamp study (0-120 min) to measure the urinary nitrogen excretion to be able to calculate protein oxidation.

Measurements of blood pressure were performed as three time readings at the beginning of the clamp, after 30 min resting position and during the clamp.

\section{Analytical methods}

Plasma concentrations of glucose were measured using the Beckman analyzer (Beckman Instruments Inc., Fullerton, CA, USA) by glucose oxidase method. Immunoreactive insulin (IRI) was determined by RIA method using an IMMUNOTECH Insulin IRMA kit (IMMUNOTECH a.s, Prague, Czech Republic) with analytical sensitivity of $0.5 \mu \mathrm{IU} / \mathrm{ml}$; intra- and interassay coefficients of variation (CV) were below or equal to 4.3 and $3.4 \%$ respectively. HbAlc was measured by HPLC method (Tosoh HLC-723 G7; Tosoh Corporation, Tokyo, Japan). This analyzer uses a non-porous ion exchanger that separates HbAlc from other fractions. The method was calibrated to IFCC reference procedure (23).

Plasma concentrations of TNF $\alpha$ were measured by immunoassay (Human TNF $\alpha$ UltraSensitive RIA kit; BioSource International, Camarillo, CA, USA; the detection limit was $<0.09 \mathrm{pg} / \mathrm{ml}$, and intra- and inter-assay CV were $5.3-6.7$ and $8.2-9.7 \%$ respectively); plasma concentrations of resistin were measured by Human Resistin ELISA kit (BioVendor Laboratory Medicine Inc., Brno, Czech Republic; the detection limit

Table 2 Primers used for RT-PCR of the subcutaneous adipose tissue samples.

\begin{tabular}{|c|c|c|c|}
\hline Gene & $\begin{array}{l}\text { Accession } \\
\text { number }\end{array}$ & Forward primer & Reverse primer \\
\hline Adiponectin & XM_290602 & $\begin{array}{l}\text { HACRP30-F: } \\
5^{\prime} \text {-GGT TCA ATG GCT TGT TTG C-3' }\end{array}$ & $\begin{array}{l}\text { HACRP30-R: } \\
\text { 5'-TCA TCC CAA GCT GAT TCT G-3' }\end{array}$ \\
\hline Leptin & NM_000230 & $\begin{array}{l}\text { Hleptin-F: } \\
\text { 5'-CCC TAA GCC TCC TTT TGC T-3' }\end{array}$ & $\begin{array}{l}\text { Hleptin-R: } \\
5^{\prime} \text {-GCT AAG AGG GGA CAA GAC A-3' }\end{array}$ \\
\hline $\mathrm{TNF} \alpha$ & $\begin{array}{r}X 02910 \\
X 02159\end{array}$ & $\begin{array}{l}\text { HTNFa-F: } \\
5^{\prime} \text {-CTA TCT GGG AGG GGT CTT C-3' }\end{array}$ & $\begin{array}{l}\text { HTNFa-R: } \\
\text { 5'-TTG GGA AGG TTG GAT GTT C-3' }\end{array}$ \\
\hline Resistin & AY207314 & $\begin{array}{l}\text { HRETN-F: } \\
\text { 5'-ATA AGC AGC ATT GGC CTG G-3' }\end{array}$ & $\begin{array}{l}\text { HRETN-R: } \\
5^{\prime} \text {-TGG CAG TGA CAT GTG GTC T-3' }\end{array}$ \\
\hline Cyclophilin & XM_090070 & $\begin{array}{l}\text { HCLPNa-F: } \\
5^{\prime} \text {-CAA ATG CTG GAC CCA ACA CA-3' }\end{array}$ & $\begin{array}{l}\text { HCLPNa-R: } \\
5^{\prime}-\text { TGC CAT CCA ACC ACT CAG TC-3' }\end{array}$ \\
\hline
\end{tabular}


A

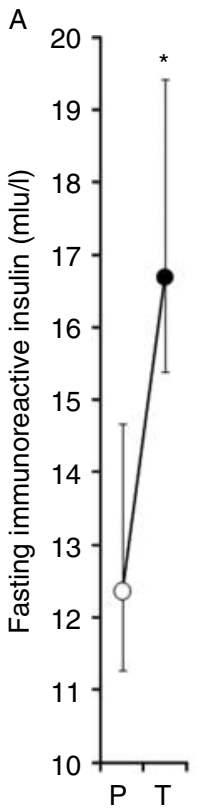

B

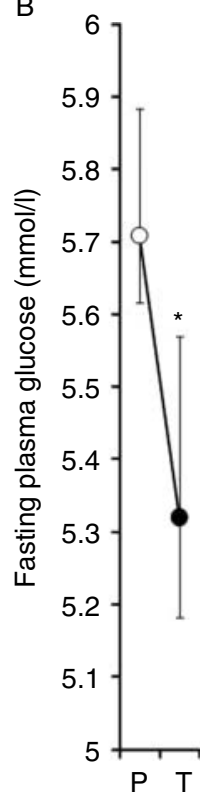

Figure 1 Effect of telmisartan treatment on fasting immunoreactive insulin and plasma glucose. The circles with error bars symbolize the group means with their $95 \%$ confidence intervals: telmisartan ( $T$; full circles) and placebo (P; open circles). For the fasting immunoreactive insulin $(A)$, the significance of the factors was as follows: telmisartan: $F=7.6, P=0.0224$; subject (inter-individual variability): $F=7.6, P=0.0029$. For the fasting plasma glucose $(B)$, the significance of the factors was as follows: telmisartan: $F=8.8$, $P=0.0129$; subject (inter-individual variability): $F=3, P=0.0392$. Statistical significance: ${ }^{\star} P<0.05$.

was $0.033 \mathrm{ng} / \mathrm{ml}$, and intra- and inter-assay $\mathrm{CV}$ were $2.8-3.4$ and $5.1-6.9 \%$ respectively); plasma concentrations of leptin were measured by Human Leptin ELISA kit (BioVendor Laboratory Medicine Inc.; the detection limit was $0.5 \mathrm{ng} / \mathrm{ml}$, and intra- and interassay CV were $3-7.5$ and $3.2-9.2 \%$ respectively); plasma concentrations of adiponectin were measured by Human Adiponectin ELISA kit (BioVendor Laboratory Medicine Inc.; the detection limit was $210 \mathrm{ng} / \mathrm{ml}$, and intra- and inter-assay $\mathrm{CV}$ were $6.4-7$ and $7.3-8.2 \%$ respectively), all according to the manufacturer's instructions.

Expression of adipokines was analysed by the realtime PCR method using the following protocol:

i) The RNA was isolated from the liquid nitrogen frozen biopsy of the human fat tissue using the RNeasy Lipid Tissue Mini kit and QIAzolLysis Reagent (Qiagen). The starting amount of $100 \mathrm{mg}$ tissue was excised from the biopsy and homogenized in $1 \mathrm{ml}$ of QIAzolLysis Reagent (guanidine thiocyanate-phenol solution) for 2 min. From the homogenate, the RNA was isolated by extraction on silica gel-based column, according to the kit handbook. Possible contamination of RNA with genomic DNA remains was taken out by DNase digestion (RNase-free DNase Set; Qiagen). This step is supposed to prevent any significant DNA amplification, e.g. by gel electrophoresis.

ii) The cDNA was synthesized using a recombinant Omniscript Reverse Transcriptase (Qiagen), ribonuclease inhibitor from human placenta (Sigma) and (dT) ${ }_{16}$ oligonucleotides.

iii) The real-time PCR procedure itself had been carried out on the DNA Engine Opticon 2 System (MJ Research, Waltham, MA, USA). HotStarTaq DNA polymerase and SYBR Green fluorescent dye (QuantiTec SYBR Green PCR kit; Qiagen) were used for the RT-PCR. To eliminate the influence of primer dimers, negative controls were used. As the reference gene, human cyclophilin was used; there is no evidence of insulin or ARB influence on cyclophilin. Primers used for RT-PCR are given in Table 2.

iv) The data were processed by Q-gene 96 software (Institute of Biochemistry and Genetics, University of Basel, Basel, Switzerland).

\section{Calculations}

Insulin action was estimated as the glucose disposal $(M)$ and metabolic clearance rate (MCR) of glucose calculated during the last $20 \mathrm{~min}$ of the clamp after correction for changes in glucose pool size (21). Calculations of substrate oxidation were made using standard equations (22). Urinary urea excretion during the clamp was corrected for changes in urea pool size (24). Nonoxidative glucose disposal (NEOX) was calculated by subtracting the rate of glucose oxidation from $M$.

Table 3 Substrate utilization before (basal) and during hyperinsulinemic euglycemic clamp (insulin) after 3-week treatment with telmisartan or placebo.

\begin{tabular}{lccccc}
\hline & \multicolumn{2}{c}{ Placebo } & & \multicolumn{2}{c}{ Telmisartan } \\
\cline { 2 - 3 } \cline { 5 - 6 } & Basal & Insulin & & Basal & Insulin \\
\hline REE $(\mathrm{kcal} / 24 \mathrm{~h})$ & $1729 \pm 386$ & $1823 \pm 337$ & & $1706 \pm 370$ & $1728 \pm 355$ \\
RQ & $0.79 \pm 0.03^{*}$ & $0.87 \pm 0.05$ & & $0.77 \pm 0.04^{*}$ & $0.86 \pm 0.03$ \\
Chox $(\mathrm{mg} / \mathrm{kg}$ per $\min )$ & $0.69 \pm 0.42^{*}$ & $1.36 \pm 0.8$ & & $0.63 \pm 0.42^{*}$ & $1.47 \pm 0.39$ \\
Fox $(\mathrm{mg} / \mathrm{kg}$ per $\mathrm{min})$ & $0.77 \pm 0.2^{*}$ & $0.48 \pm 0.2$ & & $0.71 \pm 0.32^{*}$ & $0.58 \pm 0.30$ \\
Prox $(\mathrm{mg} / \mathrm{kg}$ per $\mathrm{min})$ & $0.87 \pm 0.3^{*}$ & $0.40 \pm 0.14$ & & $0.88 \pm 0.39^{*}$ & $0.43 \pm 0.15$ \\
\hline
\end{tabular}

REE, resting energy expenditure; $R Q$, respiratory quotient; Chox, glucose oxidation; Fox, lipid oxidation; Prox, protein oxidation. Differences between telmisartan and placebo were not statistically significant. ${ }^{\star} P<0.02$ versus insulin. 


\section{Statistical analysis}

The data are expressed as means \pm s.E.M. unless indicated otherwise. Steady-state periods of both clamps were compared using Wilcoxon's paired test. The differences between time courses of both clamps were evaluated by a repeated-measures ANOVA model, including the following factors and interactions: effect of telmisartan treatment (placebo versus telmisartan) and effect of hyperinsulinemia (clamp induced) as the within factors, subject factor (represents the inter-individual variability of subjects) and telmisartan $\times$ hyperinsulinemia interaction. The last term indicated whether the shapes of the time profiles for telmisartan and placebo were different or not. The differences between subgroups were evaluated using least significant difference (LSD) multiple comparisons. The statistical significance $P<0.05$ was chosen for both ANOVA testing and multiple comparisons. Owing to a non-Gaussian data distribution in all dependent variables, the data underwent power transformations (directly in the ANOVA model) to attain distributional symmetry and a constant variance in the data as well as in residuals. The nonhomogeneities were detected using residual diagnostics. The experimental points with absolute values of studentized residual (after data transformation) $>3$ were excluded from the analysis. The fraction of such points never exceeded 5\% of the total number. Statgraphics Centurion v. XV statistical software (Stadtpoint Inc., Herndon, VA, USA) was used for the data analysis.

\section{Results}

Telmisartan compared to placebo treatment induced no differences in body weight $(89.8 \pm 19$ vs $89.8 \pm 18 \mathrm{~kg})$ but resulted in lower blood pressure, both systolic $(126 \pm 10$ vs $135 \pm 12 \mathrm{mmHg} ; P<0.03)$ and diastolic $(81 \pm 10$ vs $90 \pm 10 \mathrm{mmHg} ; P<0.01)$, lower fasting plasma glucose $(P<0.05)$ and higher fasting IRI $(P<0.05)$. Fasting plasma glucose and IRI are shown in Fig. 1. Insulin action was estimated by HEC combined with indirect calorimetry. The clamps performed after treatment with telmisartan versus placebo were comparable in terms of the mean plasma glucose concentrations $(5.29 \pm 1.9$ vs $5.34 \pm 0.3 \mathrm{mmol} / \mathrm{l}), \mathrm{CV}$ of glucose $(2.89 \pm 1.9$ vs $2.56 \pm 1.2 \%)$ and mean IRI levels. Insulin action was comparable after telmisartan and placebo. MCR $(4.15 \pm 1.0$ vs $4.08 \pm 1.9 \mathrm{ml} / \mathrm{kg}$ per $\mathrm{min}), M(4.4 \pm 1.8$ vs $3.9 \pm 1.7 \mathrm{mg} / \mathrm{kg}$ per $\mathrm{min})$ and NEOX $(4.1 \pm 1.9$ vs $3.0 \pm 2.3 \mathrm{mg} / \mathrm{kg}$ per min) did not differ between telmisartan and placebo. Similarly, EE, glucose and fat oxidations have not been statistically different comparing telmisartan and placebo (Table 3).

No significant effect of telmisartan on basal plasma concentrations of selected adipokines has been detected, except of basal plasma leptin that has significantly increased after telmisartan treatment (Fig. 2C-5C ).
Plasma concentrations of TNF $\alpha$ during HEC are shown in Fig. 2A-C. The ANOVA model indicated (Fig. 2A) a significant decrease in plasma $\mathrm{TNF} \alpha$ in telmisartan as compared to placebo (telmisartan; $P<0.05$ ), whereas no significant hyperinsulinemia effect (Fig. 2B) or interaction was detected (Fig. 2C). However, the plasma changes
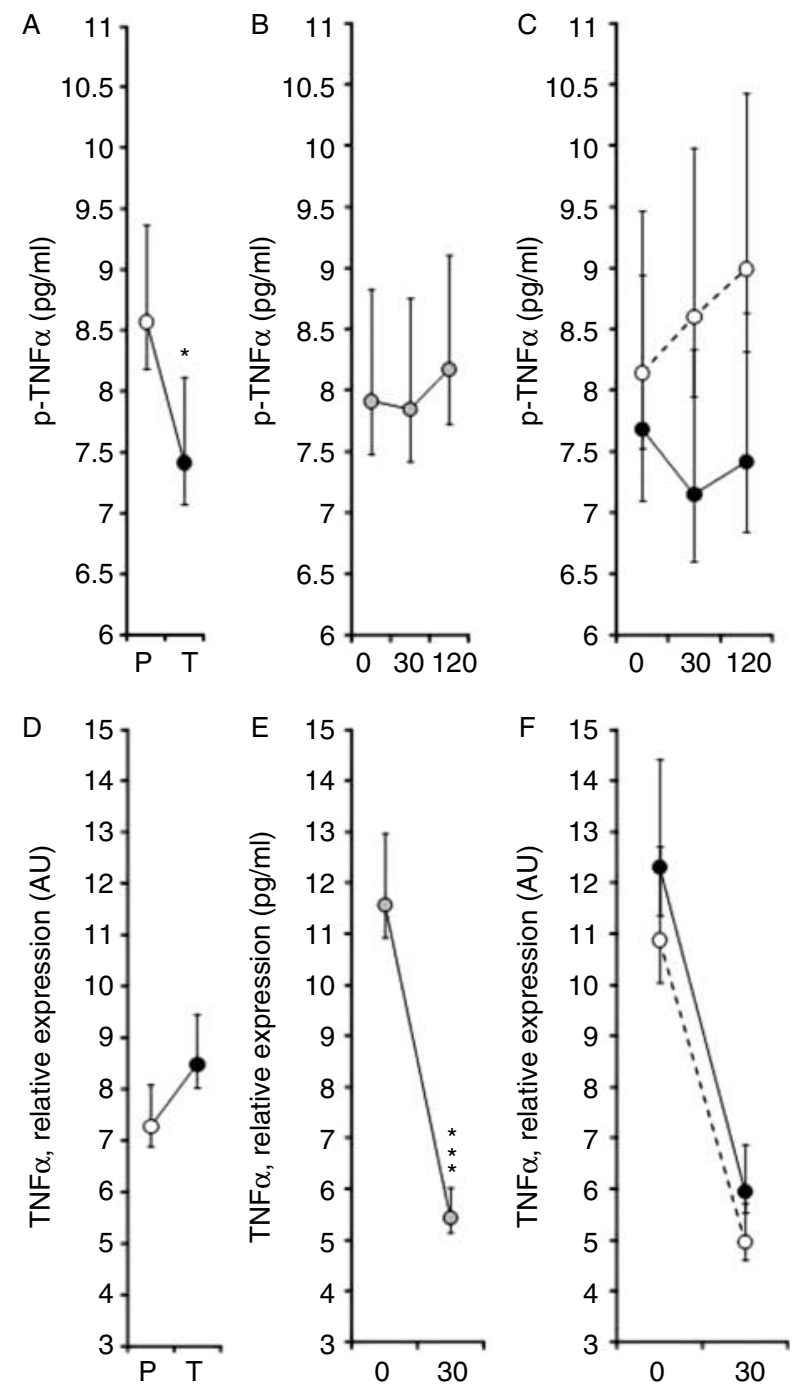

Figure 2 Effects of telmisartan treatment and the clamp-induced hyperinsulinemia on TNF $\alpha$. The circles with error bars symbolize the group means with their $95 \%$ confidence intervals: telmisartan ( $T$; full circles) and placebo (P; open circles). ( $A$ and $D)$ The effect of telmisartan is illustrated; ( $B$ and $E$ ) the effect of clamp-induced hyperinsulinemia is demonstrated; ( $\mathrm{C}$ and $\mathrm{F}$ ) the interactions between telmisartan and hyperinsulinemia are shown. For the PTNF $\alpha(\mathrm{A}-\mathrm{C})$, the significance of the factors and interactions was as follows: telmisartan: $F=4.8, P=0.0328$; subject (inter-individual variability): $F=2.7, P=0.0085$; hyperinsulinemia: $F=0.1$, $P=0.8698$; telmisartan $\times$ hyperinsulinemia: $F=0.4, P=0.6489$. For the ExTNF $\alpha(D-F)$, the significance of the factors and interactions was as follows: telmisartan: $F=3.9, P=0.0591$; subject (inter-individual variability): $F=1.8, P=0.1122$; hyperinsulinemia: $F=92, P<0.0001$; telmisartan $\times$ hyperinsulinemia: $F=0.2$, $P=0.6406$. Statistical significance: ${ }^{\star} P<0.05$, ${ }^{\star \star \star} P<0.001$. 
A
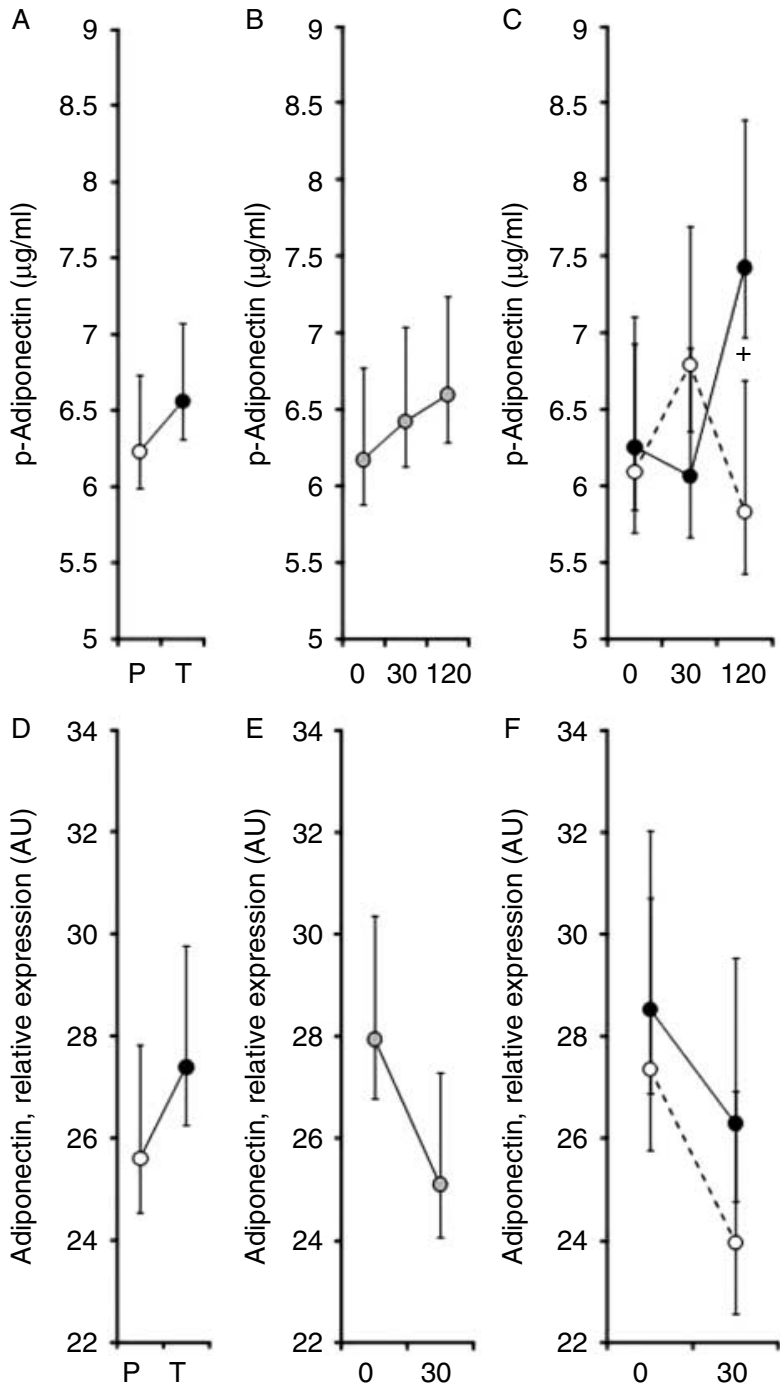

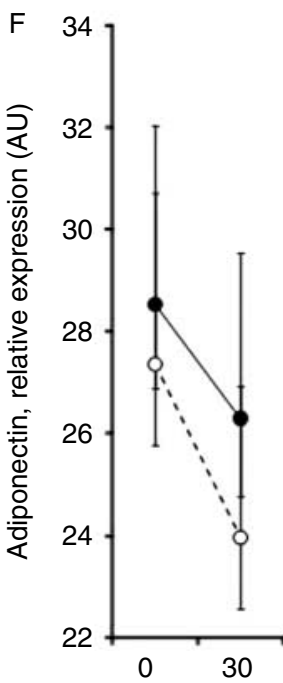

Figure 3 Effects of telmisartan treatment and the clamp-induced hyperinsulinemia on adiponectin. The circles with error bars symbolize the group means with their $95 \%$ confidence intervals: telmisartan ( $T$; full circles) and placebo (P; open circles). (A and D) The effect of telmisartan is illustrated; ( $B$ and $E$ ) the effect of clampinduced hyperinsulinemia is demonstrated; ( $C$ and $F$ ) the interactions between telmisartan and hyperinsulinemia are shown. For the plasma adiponectin $(A-C)$, the significance of the factors and interactions was as follows: telmisartan: $F=0.9, P=0.3618$; subject (inter-individual variability): $F=14.9, P<0.0001$; hyperinsulinemia: $F=0.5, P=0.6317$; telmisartan $\times$ hyperinsulinemia: $F=3.3, P=0.0429$. For the adiponectin expression $(D-F)$, the significance of the factors and interactions was as follows: telmisartan: $F=1.3, P=0.2709$; subject (inter-individual variability): $F=6.4, P<0.0001$; hyperinsulinemia: $F=3.2, P=0.0846$; telmisartan $\times$ hyperinsulinemia: $F=0.2, P=0.6756$. Statistical significance: ${ }^{+} P<0.05$ for differences between telmisartan and placebo in individual stages of HEC.

after telmisartan do not correspond with relative expression of TNF $\alpha$ in subcutaneous adipose abdominal tissue. In this study, the effect of clamp-induced hyperinsulinemia (Fig. 2E) has been found to be significant $(P<0.001)$ and no telmisartan effect was detected

(Fig. 2D), implicating the suppression of TNF $\alpha$ expression by insulin, which is not influenced by telmisartan.

Plasma adiponectin concentrations are shown in Fig. 3A-C. Plasma adiponectin concentrations have shown a different time course during insulin-stimulated conditions in telmisartan and placebo (Fig. 3C), documented by the significant telmisartan $\times$ hyperinsulinemia interaction $(P<0.05)$. A significant increase in plasma adiponectin was detected by LSD multiple comparisons in $120 \mathrm{~min}$ of HEC (0 vs $120 \mathrm{~min}$; $P<0.05)$ after telmisartan treatment, whereas no changes were seen after placebo treatment. Relative expressions of adiponectin were comparable during both treatment periods and clamps, and both telmisartan and hyperinsulinemia factors were not significant (Fig. 3D-F).

Figure $4 \mathrm{~A}-\mathrm{C}$ shows plasma leptin concentrations. Both basal and insulin-stimulated plasma leptin concentrations were significantly increased after telmisartan treatment compared to placebo treatment (telmisartan effect; $P<0.001$ ), while telmisartan did not alter the relative expressions of leptin in SAT. There was a significant decrease in leptin expressions during insulinstimulated conditions (HEC), as documented by the significant hyperinsulinemia factor $(P<0.001$; Fig. $4 \mathrm{E})$.

Plasma concentrations and tissue expressions of resistin are shown in Fig. 5. The telmisartan treatment resulted in an increase in plasma resistin concentrations, as documented by a significant telmisartan factor $(P<0.01$; Fig. 5A). The multiple comparisons tests were in accordance with ANOVA testing. Figure 5B shows the increasing plasma concentrations of resistin during insulin-stimulated conditions (HEC), as indicated by significant hyperinsulinemia factor $(P<0.001)$, whereas the effect of insulin on resistin expression was opposite (Fig. 5E). There is a significant decrease in resistin expressions during HEC in both telmisartan and placebo (hyperinsulinemia factor $P<0.01$; Fig. 5E and F) without differences between telmisartan and placebo.

\section{Discussion}

This short-term placebo-controlled crossover study demonstrate, in accordance with other studies (25), that telmisartan decreases the fasting plasma glucose and blood pressure, whereas the insulin sensitivity assessed by hyperinsulinemic clamp technique did not change after telmisartan treatment in our study population. Thus, the decrease in blood glucose cannot be explained by the improvement in insulin sensitivity. However, we have found an increase in basal plasma IRI and this finding could partly account for the decrease in plasma glucose concentrations. Additionally, we have not found any significant effect of telmisartan on the substrate utilization.

There are still controversial results dealing with the effect of telmisartan or other ARBs on insulin sensitivity 

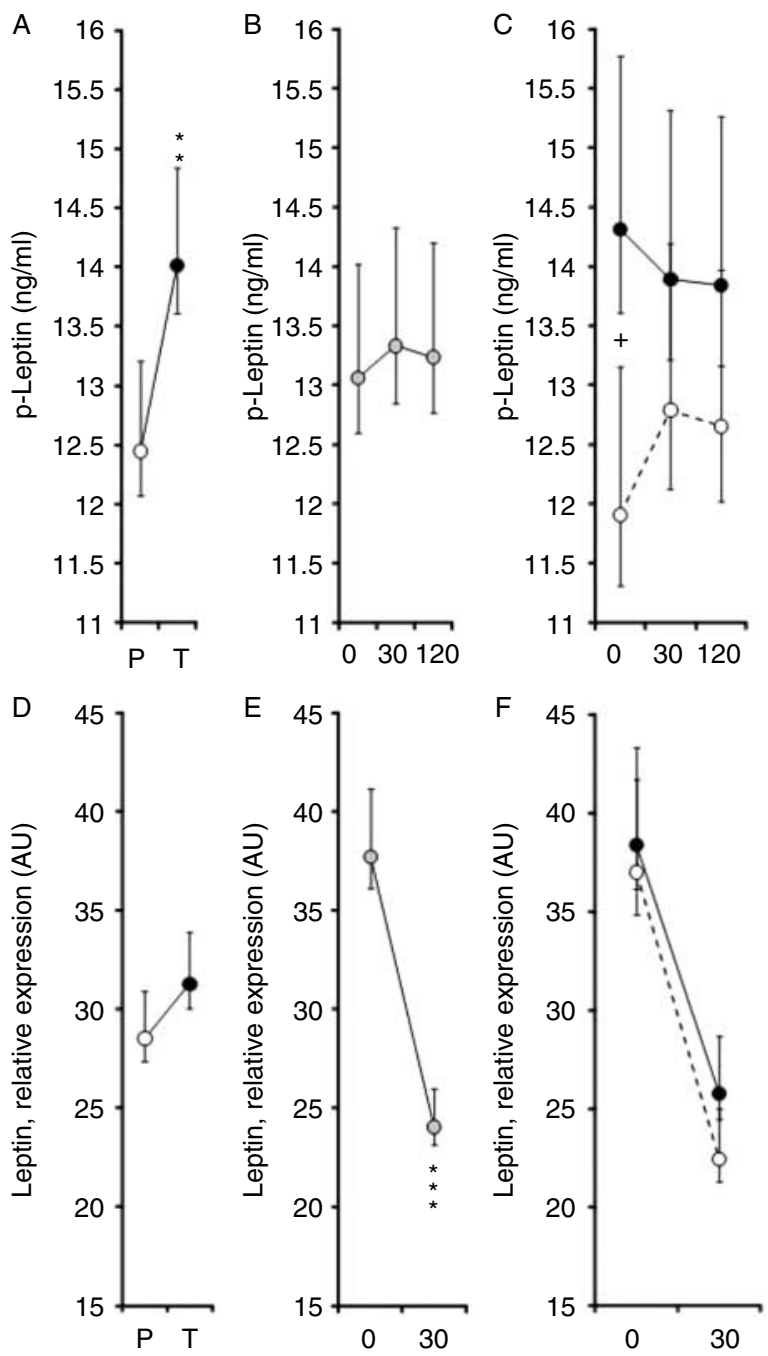

Figure 4 Effects of telmisartan treatment and the clamp-induced hyperinsulinemia on leptin. The circles with error bars symbolize the group means with their $95 \%$ confidence intervals: telmisartan ( $T$; full circles) and placebo (P; open circles). (A and D) The effect of telmisartan is illustrated; ( $B$ and $E$ ) the effect of clamp-induced hyperinsulinemia is demonstrated; $(\mathrm{C}$ and $\mathrm{F}$ ) the interactions between telmisartan and hyperinsulinemia are shown. For the plasma leptin $(A-C)$, the significance of the factors and interactions was as follows: telmisartan: $F=7.6, P=0.0079$; subject (interindividual variability): $F=35.4, P<0.0001$; hyperinsulinemia: $F=0.1, P=0.9256$; telmisartan $\times$ hyperinsulinemia: $F=0.6$, $P=0.5664$. For the leptin expressions (D-F), the significance of the factors and interactions was as follows: telmisartan: $F=2.4$, $P=0.133$; subject (inter-individual variability): $F=4.2, P=0.0012$; hyperinsulinemia: $F=56.8, P<0.0001$; telmisartan $\times$ hyperinsulinemia: $F=1, P=0.3357$. Statistical significance: ${ }^{\star} * 00.01$ for differences between initial and current state; ${ }^{* *} P<0.001$ for differences between 0 and $30 \mathrm{~min} .{ }^{+} P<0.05$ for differences between telmisartan and placebo in individual stages of HEC.

in vivo in human subjects $(13,25-27)$. In our previous study, we did not find any significant changes in insulin sensitivity after acute administration of losartan in healthy subjects (28). Clinical trials with long-term administration of ARBs (other than telmisartan) using the HEC technique for estimation of insulin sensitivity reported both an increase $(29,30)$ and no effect $(5,15$, $16,31,32$ ) of ARBs on glucose disposal in insulinresistant subjects. Telmisartan is considered to be a partial PPARG agonist, and there is experimental evidence that it has specific metabolic advantages (18). Although telmisartan has gained much attention as one of the most metabolically potent ARB compounds, there are virtually no clinical studies evaluating the effect of telmisartan on insulin sensitivity and substrate utilization using the clamp technique combined with indirect calorimetry. However, a recent study evaluating the long-term effect of telmisartan on insulin sensitivity suggests that the magnitude of PPARG stimulation by telmisartan may be modest compared with thiazolidindiones (26). On the other hand, some metabolic effects of telmisartan could be mediated independently of PPARG (33). In addition, in a rat model of metabolic syndrome, it increases EE and protects against dietary-induced obesity (19).

In our study, we have failed to show a statistically significant effect of telmisartan on insulin sensitivity and substrate utilization, but our results might be influenced by the short period of the study and the small number of patients included. To the best of our knowledge, no previous study has carefully evaluated the effect of telmisartan on insulin sensitivity and substrate utilization using the clamp technique combined with indirect calorimetry in human subjects.

The homeostasis model assessment (HOMA) index has been used in most of them $(25,34)$ and, thus, our study may be the first of its kind.

Insulin secretion has not been carefully evaluated in our study, but the improvement in blood glucose level after telmisartan treatment could be related to the improvement of $\beta$-cell function. It has been shown in experimental animals that treatment with telmisartan reduces oxidative stress and protects against islet $\beta$-cell damage and dysfunction (35).

The main finding of the present study is the significant short-term effect of telmisartan on adipokine production during insulin-stimulated conditions. Adiponectin, leptin and resistin plasma concentrations increased, whereas a decrease in TNF $\alpha$ had been found after telmisartan treatment. We also found an increase in basal leptin concentrations. The changes in plasma adipokines could not be directly explained by changes in their expressions in SAT. The short-term effect of telmisartan on adipokines during clamp-induced hyperinsulinemia has not been investigated up to this time; only the fasting plasma concentrations or adipose tissue expressions have been reported in the literature so far.

\section{Tumour necrosis factor $\alpha$}

In the present study, the telmisartan treatment was followed by a decrease in plasma TNF $\alpha$ concentrations during insulin-stimulated conditions. 

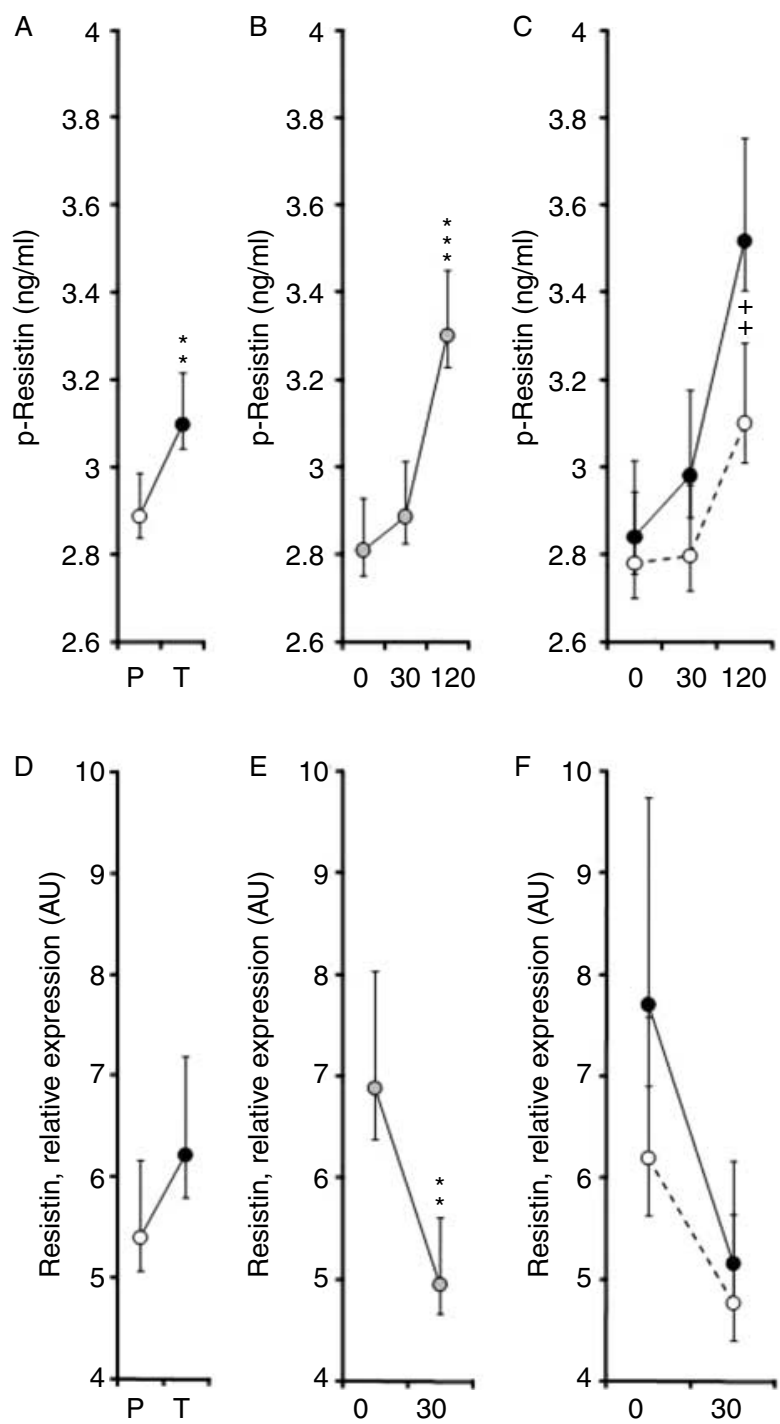

Figure 5 Effects of telmisartan treatment and the clamp-induced hyperinsulinemia on resistin. The circles with error bars symbolize the group means with their $95 \%$ confidence intervals: telmisartan ( $T$; full circles) and placebo (P; open circles). (A and D) The effect of telmisartan is illustrated; ( $B$ and $E$ ) the effect of clamp-induced hyperinsulinemia is demonstrated; $(\mathrm{C}$ and $\mathrm{F})$ the interactions between telmisartan and hyperinsulinemia are shown. For the p-resistin $(A-C)$, the significance of the factors and interactions was as follows: telmisartan: $F=9, P=0.0043$; subject (inter-individual variability): $F=40.9, P<0.0001$; hyperinsulinemia: $F=18.1$,

$P<0.0001$; telmisartan $\times$ hyperinsulinemia: $F=1.6, P=0.2033$. For the Ex-resistin (D-F), the significance of the factors and interactions was as follows: telmisartan: $F=1.9, P=0.1753$; subject (interindividual variability): $F=2.3, P=0.0382$; hyperinsulinemia: $F=10.5, P=0.0029$; telmisartan $\times$ hyperinsulinemia: $F=0.3$, $P=0.6116$. Statistical significances: ${ }^{\star \star} P<0.01,{ }^{\star \star \star} P<0.001$ for differences between initial and current state; ${ }^{++} P<0.01$ for differences between telmisartan and placebo in individual stages of HEC.

The expressions of TNF $\alpha$ in subcutaneous fat declined during hyperinsulinemia but were not affected by telmisartan treatment. The results are in agreement with the decrease in fasting $\mathrm{TNF} \alpha$ in plasma reported after 8-month telmisartan treatment in hypertensive patients after stent implantation (36) and after 6- and 12 -month administration of telmisartan in patients with metabolic syndrome (34). In addition, proinflammatory properties of TNF $\alpha$ could be attenuated by telmisartan. Inhibition of TNF $\alpha$-induced IL6 expression in vascular smooth muscle cells has been reported after telmisartan treatment (37).

\section{Adiponectin}

In our study, telmisartan increased the plasma adiponectin concentrations during insulin-stimulated conditions, whereas the expressions of adiponectin in subcutaneous fat were not changed. In contrast to some $(13,27,36,38-40)$, but not all (25), previous studies, we failed to observe any stimulatory effect of telmisartan on basal plasma adiponectin concentrations. Only the trend of an increase has been found in our insulin-resistant subjects. The results could implicate the stronger metabolic effect of telmisartan during hyperinsulinemia compared to basal (pre-prandial) conditions. ARBs-induced activation of PPARG is advocated (9). However, recently, it has been showed in 3T3-L1 adipocytes that telmisartan may stimulate adiponectin gene transcription independent of PPARG (33).

\section{Leptin}

An overall increase in circulating leptin after the telmisartan treatment was documented in the present study. Telmisartan had no significant effect on leptin expressions in SAT, but the expression declined during hyperinsulinemia. The decline was independent of telmisartan treatment. In the literature, both increase (25) and decrease (34) in fasting leptin concentrations have been reported after long-term administration of telmisartan in hypertensive and type 2 diabetic patients. Moreover, the lack of effect of telmisartan on circulating leptin has been found as well (26). Telmisartan-induced increase in plasma concentrations of leptin might attenuate body weight gain by reduced food intake with HOMA-IR improvement (25). The effect of telmisartan on leptin increase could not be clarified within the context of metabolic processes in this short time study (25). However, in accordance with some authors, we have found a telmisartan-induced increase in leptin and this finding remains to be explained.

\section{Resistin}

To our surprise, in this study, an unexpected increase in plasma resistin concentration was found during hyperinsulinemia after telmisartan administration, which is a novel observation in vivo. In contrast, Derosa et al. (40) demonstrated a decrease in plasma resistin after the telmisartan treatment in type 2 diabetic patients. 
However, only fasting concentrations were assessed, the treatment period was much longer (6 and 12 months), and the subjects were treated also by rosiglitazone (40). In our study, resistin expression decreased during the hyperinsulinemia independent of telmisartan treatment.

The changes in the plasma concentrations and tissue expressions of adiponectin, $\mathrm{TNF} \alpha$, leptin and resistin during hyperinsulinemia are discordant, and the expressions in SAT cannot explain the changes in circulating adipokines. This finding implicates the role of other sources of circulating adipokines - other fat depots or non-adipose sources (e.g. stromal vascular fraction of adipose tissue, macrophages or endothelium), which have not been addressed in the present study. However, the differences in the timing of blood sampling and biopsies should be considered as well.

In addition, the reduction in adipose tissue mass through weight loss in association with exercise can increase adiponectin concentrations and lower TNF $\alpha$ and IL6 levels in plasma, whereas drugs such as thiazolinediones increase endogenous adiponectin production $(34,41)$. Body weight and exercise had been kept stable throughout our study, and the patients were not treated with oral hypoglycemic agents. Thus, we can exclude the interference of these confounding factors with effect of telmisartan.

The present study also allowed us to roughly examine the in vivo effect of insulin on adipokines and their expressions comparing the fasting values with insulinstimulated conditions during clamp (hyperinsulinemia factor). Only a few studies have investigated the effect of insulin in vivo in human subjects. It has been shown by Westerbacka et al. (42) that insulin per se could increase the expression of a number of cytokines involved in insulin sensitivity in adipose tissue, including adiponectin and TNF $\alpha$. We did not find any significant effect of acute in vivo hyperinsulinemia induced by clamp on plasma adiponectin, leptin or TNF $\alpha$ (the hyperinsulinemia factor was not significant). On the other hand, the increase in plasma resistin concentrations has been confirmed. An increase in plasma resistin during clamp-induced hyperinsulinemia was reported in our previous study in healthy subjects (28). Similarly, Heilbronn et al. (43) found an increase in serum resistin concentrations in response to supraphysiological doses of insulin $(164 \pm 5 \mathrm{mIU} / \mathrm{l})$ in obese subjects with and without diabetes. Contrary to the result of Westerbacka et al. (42), the expressions of adiponectin did not change, and expressions of TNF $\alpha$, leptin and resistin were even suppressed by acute hyperinsulinemia. However, the present crossover study was not designed to assess the acute effect of insulin on adipokines. The control infusion to match the volume expansion during clamp was not included. Furthermore, the biopsies were taken at 30 min of clamp - very early after starting the insulin infusion, which is also an important limitation factor of our study.

The major limitations of our study are small number of subjects and/or short study duration. We did not measure peripheral blood flow. We could not exclude that the effect of telmisartan has been mediated through the blood flow improvement as well as blood pressure improvement both directly and indirectly. Moreover, we were not able to measure tissue protein levels of adipokines, and thus we could not exclude that telmisartan controls post-transcriptional rather than transcriptional regulation. However, we found the effect of telmisartan on the parameters mentioned earlier in spite of the short treatment period. The timing of biopsy at $30 \mathrm{~min}$ before equilibrium status had been achieved might have an impact on the results while assessing the acute effect of insulin when euglycemia had not been reached. The biopsy should have been more appropriately performed during the last part of the clamp after $90 \mathrm{~min}$.

We can conclude that, in patients with metabolic syndrome with impaired fasting glucose, a short-term treatment with telmisartan surprisingly increases plasma adiponectin, leptin and resistin concentrations, and decreases plasma TNF $\alpha$ levels. These results also implicate that the effect of telmisartan could be important during hyperinsulinemia, and this is the first study dealing with positive effect of telmisartan on plasma adipokines during hyperinsulinemia in patients with impaired fasting glucose. The changes in plasma concentrations of adipokines cannot be explained by their expressions in SAT. The results support the hypothesis that the changes in selected plasma adipokines might be involved in the beneficial metabolic effects of telmisartan in patients with metabolic syndrome.

\section{Declaration of interest}

The authors declare that there is no conflict of interest that could be perceived as prejudicing the impartiality of the research reported.

\section{Funding}

This work was supported by the Health Ministry of the Czech Republic (NR 9359-3, NS/10528-3 and MZO 00023001).

\section{Acknowledgements}

The authors acknowledge the skilful technical assistance of Ms Dana Lapesova and Ms Dagmar Sisakova.

\section{References}

1 Dahlof B, Devereux RB, Kjeldsen SE, Julius S, Beevers G, de Faire U, Fyhrquist F, Ibsen H, Kristiansson K, Lederballe-Pedersen O, Lindholm LH, Nieminen MS, Omvik P, Oparil S \& Wedel H. Cardiovascular morbidity and mortality in the losartan intervention for endpoint reduction in hypertension study (LIFE): a randomised trial against atenolol. Lancet 2002359 995-1003. (doi:10.1016/S0140-6736(02)08089-3)

2 Julius S, Kjeldsen SE, Weber M, Brunner HR, Ekman S, Hansson L, Hua T, Laragh J, McInnes GT, Mitchell L, Plat F, Schork A, Smith B \& Zanchetti A. Outcomes in hypertensive patients at high 
cardiovascular risk treated with regimens based on valsartan or amlodipine: the VALUE randomised trial. Lancet $2004 \mathbf{3 6 3}$ 2022-2031. (doi:10.1016/S0140-6736(04)16451-9)

3 Jandeleit-Dahm KA, Tikellis C, Reid CM, Johnston CI \& Cooper ME. Why blockade of the renin-angiotensin system reduces the incidence of new-onset diabetes. Journal of Hypertension 200523 463-473. (doi:10.1097/01.hjh.0000160198.05416.72)

4 Schupp M, Janke J, Clasen R, Unger T \& Kintscher U. Angiotensin type 1 receptor blockers induce peroxisome proliferator-activated receptor-gamma activity. Circulation 2004109 2054-2057. (doi:10.1161/01.CIR.0000127955.36250.65)

5 Scheen AJ. Prevention of type 2 diabetes mellitus through inhibition of the renin-angiotensin system. Drugs $2004 \mathbf{6 4}$ 2537-2565. (doi:10.2165/00003495-200464220-00004)

6 Staels B \& Fruchart JC. Therapeutic roles of peroxisome proliferatoractivated receptor agonists. Diabetes 200554 2460-2470. (doi:10. 2337/diabetes.54.8.2460)

7 Furuhashi M, Ura N, Takizawa H, Yoshida D, Moniwa N, Murakami H, Higashiura K \& Shimamoto K. Blockade of the renin-angiotensin system decreases adipocyte size with improvement in insulin sensitivity. Journal of Hypertension 2004 22 1977-1982. (doi:10.1097/00004872-200410000-00021)

8 Sharma AM, Janke J, Gorzelniak K, Engeli S \& Luft FC. Angiotensin blockade prevents type 2 diabetes by formation of fat cells. Hypertension 200240 609-611. (doi:10.1161/01.HYP.0000036448.44066.53)

9 Clasen R, Schupp M, Foryst-Ludwig A, Sprang C, Clemenz M, Krikov M, Thone-Reineke C, Unger T \& Kintscher U. PPARgammaactivating angiotensin type- 1 receptor blockers induce adiponectin. Hypertension $2005 \mathbf{4 6}$ 137-143. (doi:10.1161/01.HYP. $0000168046.19884 .6 a)$

10 Komiya N, Hirose H, Kawabe H, Itoh H \& Saito I. Effects of telmisartan therapy on metabolic profiles and serum high molecular weight (HMW)-adiponectin level in Japanese male hypertensive subjects with abdominal obesity. Journal of Atherosclerosis and Thrombosis $2009 \mathbf{1 6} 137-142$.

11 Makita S, Abiko A, Naganuma Y, Moriai Y \& Nakamura M. Effects of telmisartan on adiponectin levels and body weight in hypertensive patients with glucose intolerance. Metabolism 2008 57 1473-1478. (doi:10.1016/j.metabol.2008.05.019)

12 Levy BI. How to explain the differences between renin-angiotensin system modulators. American Journal of Hypertension 2005 9S 134S-141S. (doi:10.1016/j.amjhyper.2005.05.005)

13 Benndorf RA, Rudolph T, Appel D, Schwedhelm E, Maas R, Schulze F, Silberhorn E \& Boger RH. Telmisartan improves insulin sensitivity in nondiabetic patients with essential hypertension. Metabolism 200655 1159-1164. (doi:10.1016/j.metabol.2006. 04.013)

14 Dyck DJ, Heigenhauser GJ \& Bruce CR. The role of adipokines as regulators of skeletal muscle fatty acid metabolism and insulin sensitivity. Acta Physiologica 2006186 5-16. (doi:10.1111/j. 1748-1716.2005.01502.x)

15 Eriksson JW, Jansson PA, Carlberg B, Hagg A, Kurland L, Svensson MK, Ahlstrom H, Strom C, Lonn L, Ojbrandt K, Johansson L \& Lind L. Hydrochlorothiazide, but not Candesartan, aggravates insulin resistance and causes visceral and hepatic fat accumulation: the mechanisms for the diabetes preventing effect of Candesartan (MEDICA) Study. Hypertension 200852 1030-1037. (doi:10.1161/HYPERTENSIONAHA.108.119404)

16 Fogari R, Derosa G, Zoppi A, Lazzari P, Corradi L, Preti P \& Mugellini A. Effect of delapril/manidipine vs olmesartan/ hydrochlorothiazide combination on insulin sensitivity and fibrinogen in obese hypertensive patients. Internal Medicine 2008 47 361-366. (doi:10.2169/internalmedicine.47.0449)

17 Kurtz TW. New treatment strategies for patients with hypertension and insulin resistance. American Journal of Medicine 2006119 S24-S30. (doi:10.1016/j.amjmed.2006.01.011)

18 Benson SC, Pershadsingh HA, Ho CI, Chittiboyina A, Desai P, Pravenec M, Qi N, Wang J, Avery MA \& Kurtz TW. Identification of telmisartan as a unique angiotensin II receptor antagonist with selective PPARgamma-modulating activity. Hypertension $2004 \mathbf{4 3}$ 993-1002. (doi:10.1161/01.HYP.0000123072.34629.57)
19 Sugimoto K, Kazdova L, Qi NR, Hyakukoku M, Kren V, Simakova M, Zidek V, Kurtz TW \& Pravenec M. Telmisartan increases fatty acid oxidation in skeletal muscle through a peroxisome proliferator-activated receptor-gamma dependent pathway. Journal of Hypertension 200826 1209-1215. (doi:10. 1097/HJH.0b013e3282f9b58a)

20 Grundy SM, Cleeman JI, Daniels SR, Donato KA, Eckel RH, Franklin BA, Gordon DJ, Krauss RM, Savage PJ, Smith SC Jr, Spertus JA \& Costa F. Diagnosis and management of the metabolic syndrome: an American Heart Association/National Heart, Lung, and Blood Institute Scientific Statement. Circulation 2005112 2735-2752. (doi:10.1161/CIRCULATIONAHA.105.169404)

21 DeFronzo RA, Tobin JD \& Andres R. Glucose clamp technique: a method for quantifying insulin secretion and resistance. American Journal of Physiology 1979237 E214-E223.

22 Ferrannini E. The theoretical bases of indirect calorimetry: a review. Metabolism 198837 287-301. (doi:10.1016/00260495(88)90110-2)

23 Mosca A, Goodall I, Hoshino T, Jeppsson JO, John WG, Little RR, Miedema K, Myers GL, Reinauer H, Sacks DB \& Weykamp CW. Global standardization of glycated hemoglobin measurement: the position of the IFCC Working Group. Clinical Chemistry and Laboratory Medicine 200745 1077-1080. (doi:10.1515/CCLM. 2007.246)

24 Tappy L, Owen OE \& Boden G. Effect of hyperinsulinemia on urea pool size and substrate oxidation rates. Diabetes 198837 1212-1216. (doi:10.2337/diabetes.37.9.1212)

25 Usui I, Fujisaka S, Yamazaki K, Takano A, Murakami S, Yamazaki Y, Urakaze M, Hachiya $H$, Takata $M$, Senda $S$, Iwata M, Satoh A, Sasaoka T, Ak ND, Temaru R \& Kobayashi M. Telmisartan reduced blood pressure and HOMA-IR with increasing plasma leptin level in hypertensive and type 2 diabetic patients. Diabetes Research and Clinical Practice 200777 210-214. (doi:10. 1016/j.diabres.2006.11.014)

26 Nakamura T, Kawachi K, Saito Y, Saito T, Morishita K, Hoshino J, Hosoi T, Iwasaki T, Ohyama Y \& Kurabayashi M. Effects of ARB or ACE-inhibitor administration on plasma levels of aldosterone and adiponectin in hypertension. International Heart Journal 200950 501-512. (doi:10.1536/ihj.50.501)

27 Negro R \& Hassan H. The effects of telmisartan and amlodipine on metabolic parameters and blood pressure in type 2 diabetic, hypertensive patients. Journal of the Renin-Angiotensin-Aldosterone System 20067 243-246. (doi:10.3317/jraas.2006.045)

28 Krusinova E, Klementova M, Kopecky J, Wohl P, Kazdova L, Mlejnek P, Pravenec M, Hill M \& Pelikanova T. Effect of acute hyperinsulinaemia with and without angiotensin II type 1 receptor blockade on resistin and adiponectin concentrations and expressions in healthy subjects. European Journal of Endocrinology 2007157 443-449. (doi:10.1530/EJE-07-0034)

29 Paolisso G, Tagliamonte MR, Gambardella A, Manzella D, Gualdiero P, Varricchio G, Verza M \& Varricchio M. Losartan mediated improvement in insulin action is mainly due to an increase in non-oxidative glucose metabolism and blood flow in insulin-resistant hypertensive patients. Journal of Human Hypertension 199711 307-312. (doi:10.1038/s.jph.1000434)

30 Furuhashi M, Ura N, Higashiura K, Murakami H, Tanaka M, Moniwa N, Yoshida D \& Shimamoto K. Blockade of the reninangiotensin system increases adiponectin concentrations in patients with essential hypertension. Hypertension $2003 \mathbf{4 2}$ 76-81. (doi:10.1161/01.HYP.0000078490.59735.6E)

31 Fogari R, Zoppi A, Preti P, Fogari E, Malamani G \& Mugellini A. Differential effects of ACE-inhibition and angiotensin II antagonism on fibrinolysis and insulin sensitivity in hypertensive postmenopausal women. American Journal of Hypertension 2001 14 921-926. (doi:10.1016/S0895-7061(01)02140-9)

32 Yavuz D, Koc M, Toprak A, Akpinar I, Velioglu A, Deyneli O, Haklar G \& Akalin S. Effects of ACE inhibition and AT1receptor antagonism on endothelial function and insulin sensitivity in essential hypertensive patients. Journal of the ReninAngiotensin-Aldosterone System 20034 197-203. (doi:10.3317/ jraas.2003.032) 
33 Moriuchi A, Yamasaki H, Shimamura M, Kita A, Kuwahara H, Fujishima K, Satoh T, Fukushima K, Fukushima T, Hayakawa T, Mizuguchi H, Nagayama Y, Abiru N, Kawasaki E \& Eguchi K. Induction of human adiponectin gene transcription by telmisartan, angiotensin receptor blocker, independently on PPAR-gamma activation. Biochemical and Biophysical Research Communications 2007356 1024-1030. (doi:10.1016/j.bbrc.2007.03.084)

34 Derosa G, Cicero AF, D'Angelo A, Ragonesi PD, Ciccarelli L, Piccinni MN, Pricolo F, Salvadeo SA, Ferrari I, Gravina A \& Fogari R. Telmisartan and irbesartan therapy in type 2 diabetic patients treated with rosiglitazone: effects on insulin-resistance, leptin and tumor necrosis factor-alpha. Hypertension Research 200629 849-856. (doi:10.1291/hypres.29.849)

35 Hasegawa G, Fukui M, Hosoda H, Asano M, Harusato I, Tanaka M, Shiraishi E, Senmaru T, Sakabe K, Yamasaki M, Kitawaki J, Fujinami A, Ohta M, Obayashi H \& Nakamura N. Telmisartan, an angiotensin II type 1 receptor blocker, prevents the development of diabetes in male Spontaneously Diabetic Torii rats. European Journal of Pharmacology 2009605 164-169. (doi:10.1016/ j.ejphar.2009.01.001)

36 Hong SJ, Shim WJ, Choi JI, Joo HJ, Shin SY, Park SM, Lim SY \& Lim DS. Comparison of effects of telmisartan and valsartan on late lumen loss and inflammatory markers after sirolimus-eluting stent implantation in hypertensive patients. American Journal of Cardiology 2007100 1625-1629. (doi:10.1016/j.amjcard.2007. 06.068)

37 Tian Q, Miyazaki R, Ichiki T, Imayama I, Inanaga K, Ohtsubo H, Yano K, Takeda K \& Sunagawa K. Inhibition of tumor necrosis factoralpha-induced interleukin- 6 expression by telmisartan through cross-talk of peroxisome proliferator-activated receptor-gamma with nuclear factor kappaB and CCAAT/enhancer-binding protein-beta. Hypertension 200953 798-804. (doi:10.1161/HYPERTENSIONAHA.108.126656)
38 Nagel JM, Tietz AB, Goke B \& Parhofer KG. The effect of telmisartan on glucose and lipid metabolism in nondiabetic, insulin-resistant subjects. Metabolism 200655 1149-1154. (doi:10.1016/ j.metabol.2006.04.011)

39 Mori Y, Itoh Y \& Tajima N. Telmisartan improves lipid metabolism and adiponectin production but does not affect glycemic control in hypertensive patients with type 2 diabetes. Advances in Therapy 200724 146-153. (doi:10.1007/BF02850002)

40 Derosa G, Fogari E, D’Angelo A, Cicero AF, Salvadeo SA, Ragonesi PD, Ferrari I, Gravina A, Fassi R \& Fogari R. Metabolic effects of telmisartan and irbesartan in type 2 diabetic patients with metabolic syndrome treated with rosiglitazone. Journal of Clinical Pharmacy and Therapeutics 200732 261-268. (doi:10. 1111/j.1365-2710.2007.00820.x)

41 Ronti T, Lupattelli G \& Mannarino E. The endocrine function of adipose tissue: an update. Clinical Endocrinology $2006 \mathbf{6 4}$ 355-365. (doi:10.1111/j.1365-2265.2006.02474.x)

42 Westerbacka J, Corner A, Kannisto K, Kolak M, Makkonen J, Korsheninnikova E, Nyman T, Hamsten A, Fisher RM \& Yki-Jarvinen H. Acute in vivo effects of insulin on gene expression in adipose tissue in insulin-resistant and insulin-sensitive subjects. Diabetologia 200649 132-140. (doi:10.1007/s00125-0050075-5)

43 Heilbronn LK, Rood J, Janderova L, Albu JB, Kelley DE, Ravussin E \& Smith SR. Relationship between serum resistin concentrations and insulin resistance in nonobese, obese, and obese diabetic subjects. Journal of Clinical Endocrinology and Metabolism 200489 1844-1848. (doi:10.1210/jc.2003-031410)

Received 14 June 2010

Accepted 14 July 2010 